\title{
O SUBSÍDIO CRUZADO ÀS EXPORTAÇÕES DE AÇÚCAR DA UNIÃO EUROPÉIA: IMPACTO SOBRE AS EXPORTAÇÕES BRASILEIRAS DE AÇÚCAR*
}

\author{
Cinthia Cabral da Costa ${ }^{\S}$ \\ Heloísa Lee Burnquist
}

\begin{abstract}
RESUMO
Este trabalho apresenta e discute um procedimento para quantificar os efeitos dos subsídios cruzados auferidos pelas exportações de açúcar refinado da União Européia (UE) sobre a exportação brasileira de açúcar. Estimou-se, a princípio, o impacto do subsídio sobre o preço ao qual o açúcar refinado é exportado pela UE. Esse efeito-preço foi associado à elasticidade-preço cruzada da demanda de importação de açúcar. A seguir, procedeu-se à simulação da eliminação do subsídio ao açúcar na União Européia para estimar o impacto dessa mudança sobre a demanda de importação pelo açúcar brasileiro refinado. Essa demanda de importação foi limitada, no entanto, apenas aos mercados comuns ao Brasil e à EU, durante o período da análise. Esse impacto foi desagregado em termos das principais regiões produtoras do País, tendo-se verificado que o incremento pela importação do açúcar da região Centro-Sul do Brasil seria bem mais expressivo, da ordem de seis vezes superior ao estimado para a região Norte-Nordeste.
\end{abstract}

Palavras-chave: subsídio cruzado, açúcar, exportação, Brasil, UE.

\begin{abstract}
This work presents and discusses a procedure to quantify the effects that cross subsidies provided for the EU refined sugar exports have upon Brazilian exports. This price effect was associated to cross price elasticities of sugar import demand for the EU sugar. This was followed by a simulation of an elimination of sugar subsidies by the European Union, to evaluate the effect of this change upon the import demand of Brazilian refined sugar. This import demand was restricted, however, to those importers that buy sugar from both exporters, Brazil and UE through the period taken of the analysis. The effect was disaggregated in terms of the main production region of the country, showing that the sugar import increase by Center-South Brazil would be more expressive, of about six times superior than the estimated impact upon the North- Northeastern region.
\end{abstract}

Key words: cross-subsidies, sugar, export, Brazil, EU.

JEL classification: F13.

* Este trabalho é parte da tese de doutorado da primeira autora, sob orientação da segunda autora.

$\S$ Pesquisadora do Instituto de Estudos do Comércio e Negociações Internacionais - ICONE. Professora doutora da FEAD-Minas. Rua Santos Dumont, 380. CEP: 36800-000. Carangola, Minas Gerais. E-mail: costa-cinthia@uol.com.br.

a. Professora doutora da Esalq/USP. Departamento de Economia, Administração e Sociologia - DEAS. Piracicaba, São Paulo. C.P. 9. E-mail: hlburnqu@esalq.usp.br.

Recebido em setembro de 2004. Aceito em junho de 2005. 


\section{INTRODUÇÃO}

Como proceder para resolver as distorções provocadas nos mercados internacionais por medidas protecionistas, tais como os subsídios, tem sido uma questão recorrente nas negociações que envolvem os produtos agrícolas e agroindustriais. Este tema é de importância particular para o açúcar, cujo mercado é considerado um dos mais distorcidos no contexto mundial. Isso se deve à manutenção de políticas que protegem os mercados nacionais e estimulam a produção interna via transferências substanciais, particularmente por parte de países ricos, como é o caso do bloco da União Européia (UE-15).

O regime de açúcar desse bloco econômico, que prevalece desde 1967, não apenas assegurou a auto-suficiência na produção da commodity, como também transformou a UE de importador líquido de açúcar, na década de 1970, a maior exportador mundial, a partir de 1980. Como líder mundial, as exportações dos países europeus vêm sendo cerca de $50 \%$ das exportações mundiais de açúcar refinado, dando continuidade à sua complexa política de sustentação de preços domésticos. Acredita-se que essa política tem assegurado retornos suficientemente elevados para estimular a produção e a oferta de excedentes a preços competitivos no mercado mundial. Frandsen et al. (2001) referem-se a tal mecanismo como o subsídio cruzado para as exportações de açúcar. Na realidade, existem diversas definições para o termo subsídio cruzado. No contexto do presente estudo, referese ao mecanismo pelo qual os subsídios providos a uma iniciativa lucrativa são transferidos para outra. Embora se afirme que as exportações da UE não são subsidiadas além do limite estabelecido no Acordo do GATT, boa parte dos recursos transferidos aos produtores europeus para produzir um certo volume de quota do produto possibilita a geração de excedentes exportáveis além do volume regulamentado, ainda que este não seja transferido diretamente ao produtor de açúcar para a geração desses excedentes. Esses são, portanto, indiretamente subsidiados pelas quotas, caracterizando o subsídio indireto. Esta posição foi confirmada em parecer de painel apresentado pela OMC:

"...the basis of those facts, Australia argued the cross-subsidies provided to $C$ sugar exports through the income and price support for quota beet and quota sugar operated directly or indirectly to increase exports of $C$ sugar within the sense of Article XVI of GATT 1994, including Article XVI:4.[56] The panel found that C-sugar exports are effectively cross-subsidised by EU support provided for the production of quota sugar (" $A$ " and " $B$ " sugar)." (Australian, 2005).

Em 2002, um grupo de países exportadores de açúcar, composto pelo Brasil, Austrália e Tailândia, solicitou a abertura de Painel na Organização Mundial do Comércio - OMC, para averiguar a existência de envolvimento de recursos governamentais na exportação da commodity a preços inferiores ao custo médio total da produção, o que caracteriza a prática de subsídios cruzados.

Existem evidências de que a produção do bloco não pode competir com os grandes produtores e exportadores mundiais. Os custos de produção de açúcar de beterraba são consideravelmente superiores aos da produção do açúcar de cana. (Silveira e Burnquist, 2004). Além disso, é importante considerar que o preço pago ao produtor doméstico na UE vem sendo mantido em nível bastante superior ao do mercado mundial. (Burnquist e Bacchi, 2002).

A despeito das evidências de práticas protecionistas e distorcidas, a UE tem argumentado que a descontinuidade de sua política deve trazer prejuízos líquidos para grande parte dos países pobres que exportam açúcar bruto para o bloco, dentro de acordos preferenciais, como é o caso das

1 Mais detalhes sobre a história e o funcionamento da política agrícola adotada pela UE podem ser encontrados em Marques (1993). 
ex-colônias da África, Caribe e Pacífico (ACP). Os mais importantes exportadores de açúcar para a União Européia dentro deste grupo são: Maurício, Fiji, Guiana, Jamaica e Suazilândia.

O presente trabalho foi desenvolvido para se constituir em uma contribuição a iniciativas dessa natureza, pela identificação de modelos econômicos de equilíbrio parcial, utilizados para mensurar as perdas de comércio em países competitivos. Neste estudo, os modelos selecionados foram aplicados para identificar o aumento potencial das exportações brasileiras de açúcar no caso de eliminação dos subsídios cruzados às exportações deste produto na UE. Os modelos descritos podem ser aplicados a estudos de outros mercados, onde ocorre o subsídio às exportações.

\subsection{O regime de açúcar da UE: enfoque para as quotas de produção e o subsídio cruzado}

Aparentemente, o subsídio cruzado às exportações de açúcar da UE resulta de uma sistemática comercial complexa de importação e exportação. Embora o bloco econômico seja considerado auto-suficiente na produção do volume de açúcar que consome, vem se mantendo entre os maiores importadores de açúcar bruto e refinado, tanto em volume como em valor. Observa-se que aproximadamente $90 \%$ da importação de açúcar refinado da UE ocorre intrabloco. No entanto, tomando-se como base o período analisado de 1994 a 2001, identifica-se que mais de $70 \%$ do volume exportado de açúcar refinado pela UE foi extrabloco.

Sob o regime de açúcar da UE, o volume de produção que recebe preços sustentados é limitado por um sistema de quotas distribuídas aos produtores. A quota A, cujos preços são mais elevados, é definida como o volume necessário para atender ao consumo doméstico de açúcar entre os países do bloco. Uma quantidade adicional, chamada de quota B, inclui o açúcar que ultrapassa a quota definida para o consumo doméstico, porém recebe, ainda assim, preços sustentados como uma "compensação" por não ter sido vendida ao preço doméstico (ou seja, ao valor da quota A). A produção que excede a soma das quotas A e B passa a compor o que se denomina de açúcar C, que deve ser voltado para o mercado externo e para o qual não se estabelece qualquer nível de preços sustentados. $^{2}$

Ainda que não se atribuam subsídios diretos a essa produção excedente que compõe a quota C, a exportação de um volume expressivo pelo bloco tem suscitado sérios questionamentos. Isto tem indicado que a sustentação proporcionada por meio do regime de açúcar constitui-se na única forma de tornar o açúcar europeu competitivo no mercado internacional. Daí a denominação de subsídios cruzados ao instrumento que possibilita a manutenção do bloco como segundo maior exportador mundial de açúcar.

Frandsen et al. (2001) procuraram modelar a política de açúcar da UE, enfatizando que a oferta de açúcar apresenta um padrão bastante estável, com alguns países mostrando alta produção, que resulta na geração de grandes volumes da quota $\mathrm{C}$, enquanto outros não conseguem nem mesmo preencher a sua quota. Os autores consideram que tais diferenças devem ser explicadas, dentre outros fatores, por diferenças nas funções de custo marginal entre os países do bloco econômico. Os autores indicaram que países como Itália e Finlândia e, principalmente, Portugal e Grécia podem ter dificuldades em produzir a quota A, uma vez que apresentam custo marginal acima do preço estabelecido para esta quota. De forma semelhante, o custo marginal de produção da Suécia, Holanda e Irlanda podem impedir esses países de produzirem dentro da quota B, por serem supe-

2 A quota A vem sendo fixada em 11,98 milhões de toneladas de equivalente açúcar branco desde 1995/96, sendo distribuída entre os 15 países que compunham a UE. A quota B tem sido muito menor, estabelecida em 2,61 milhões de toneladas. Não se estabelece limite para a produção de açúcar C, que representa todo o volume que excede as quotas A e B, e que representa o excedente exportável de produção. 
riores ao preço estabelecido nesta quota. Dinamarca, Bélgica e Espanha podem abastecer as quotas nacionais, pois apresentam custo marginal menor do que o preço definido pela quota $\mathrm{B}$.

Os maiores produtores, como é o caso da França, Alemanha, Áustria e Reino Unido, podem produzir açúcar em volume suficientemente elevado, a ponto de gerar considerável excedente exportável (quota C), por apresentar custo marginal próximo ao do preço mundial.

Os autores concluíram que esse efeito das políticas de sustentação sobre a produção expressa uma forma de subsidiar indiretamente as exportações de açúcar, uma vez que a concessão do subsídio cruzado para essas exportações é uma política que encoraja a produção para níveis bastante superiores aos da demanda doméstica.

\subsection{As exportações brasileiras de açúcar refinado}

Embora o Brasil tenha uma maior participação no mercado de açúcar bruto, defronta-se com a concorrência da União Européia no mercado de açúcar refinado, de forma que o presente trabalho concentra-se na análise desse mercado, selecionando, ainda, um conjunto de países que importaram a commodity, tanto do Brasil como da União Européia, no período tomado para a análise.

A liberação das exportações brasileiras a partir da safra 1994/95 foi acompanhada de um incremento da produção e das exportações de açúcar, indicando que a realocação de recursos, sem qualquer intervenção governamental, estimulou a expansão da produção observada pelo País. A Figura 1 ilustra o aumento das exportações brasileiras de açúcar na segunda metade da década de 1990. Observa-se nesta figura a diferença regional nas exportações, em que a crescente participação das exportações originadas no Estado de São Paulo, decorrentes do processo de desregulamentação, foi a principal razão interna para o aumento das exportações brasileiras. Segundo Costa e Burnquist (2003), o efeito da competitividade sobre o aumento das exportações brasileiras de açúcar na segunda metade da década de 1990 ocorreu de maneira significativa na região Centro-Sul (explicando $89 \%$ do aumento das exportações). Na região Norte-Nordeste, o aumento das exportações de açúcar foi explicado apenas pelo crescimento do tamanho do mercado mundial de açúcar e pelo incremento das importações dos países que importaram dessa região.

Destacando ainda mais as exportações de açúcar da região Centro-Sul, tem-se que, segundo dados de Brasil (2003b), do total das exportações do capítulo 17 do Sistema Harmonizado (que corresponde a açúcares e outros produtos de confeitaria), no período de 1996 a 2001: na região Centro-Sul, 58,8\% foi de açúcar bruto (correspondente ao código NCM 1701.11.00) e 40,2\% foi de açúcar refinado (principal tipo de açúcar exportado, código NCM 1701.99 .00 no Brasil). ${ }^{3}$ Por outro lado, as exportações de açúcar da região Norte-Nordeste, nesse mesmo período, foram de 81,9\% de açúcar bruto e 16,4\% de açúcar refinado. Portanto, verifica-se a importância da análise regional dos impactos sobre as exportações brasileiras de açúcar refinado com a eliminação da política de subsídios cruzados sobre as exportações de açúcar da UE.

3 Esta distinção entre açúcar bruto e refinado nos códigos descritos foi também utilizada em Brasil (2003a). 
Figura 1 - Média das exportações de açúcar total das regiões Norte-Nordeste e Centro-Sul do Brasil nos subperíodo de 1990/1995 e 1996/2001

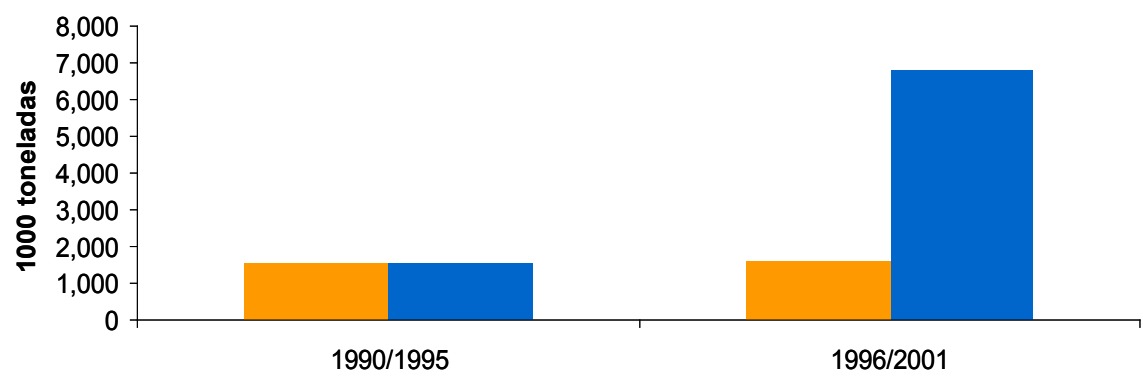

Norte-Nordeste $\square$ Centro-Sul

Fonte: Brasil (2003b).

Apesar desse incremento nas exportações brasileiras, vem se tornando cada vez mais evidente a importância de analisar o efeito das medidas protecionistas impostas por países desenvolvidos para o açúcar, como é o caso da União Européia, para a exploração plena do potencial do País nesse mercado.

\section{Metodologia}

O fluxograma apresentado na Figura 2 descreve os modelos a serem estimados e as equações calculadas para identificar o impacto sobre as exportações de açúcar refinado no Brasil.

Conforme descrito na Figura 2, o modelo de Gardner (1987) foi utilizado como base para o delineamento de um contexto analítico para estimar o efeito de uma redução nos subsídios sobre o volume e o preço de exportação da UE. Associado a este efeito estimou-se a elasticidade-preço cruzada para se chegar ao aumento das exportações brasileiras resultantes do aumento no preço das exportações européias.

Para analisar os efeitos de reduções no nível de subsídio sobre as exportações de um país relevante no comércio internacional, Gardner (1987) partiu dos mesmos pressupostos básicos de oferta e de demanda, descritos pelas equações (1) e (2). Entretanto, considerou que o preço de oferta do país exportador se altera como resultado de um subsídio aplicado sobre o preço demandado pelos importadores. 
Figura 2 - Fluxograma dos modelos estimados para avaliar os impactos dos equivalentes subsídios incidentes nas exportações da UE, sobre as exportações brasileiras de açúcar refinado

Impactos do equivalente subsídio incidentes nas exportações da UE sobre as exportações brasileiras de açúcar refinado

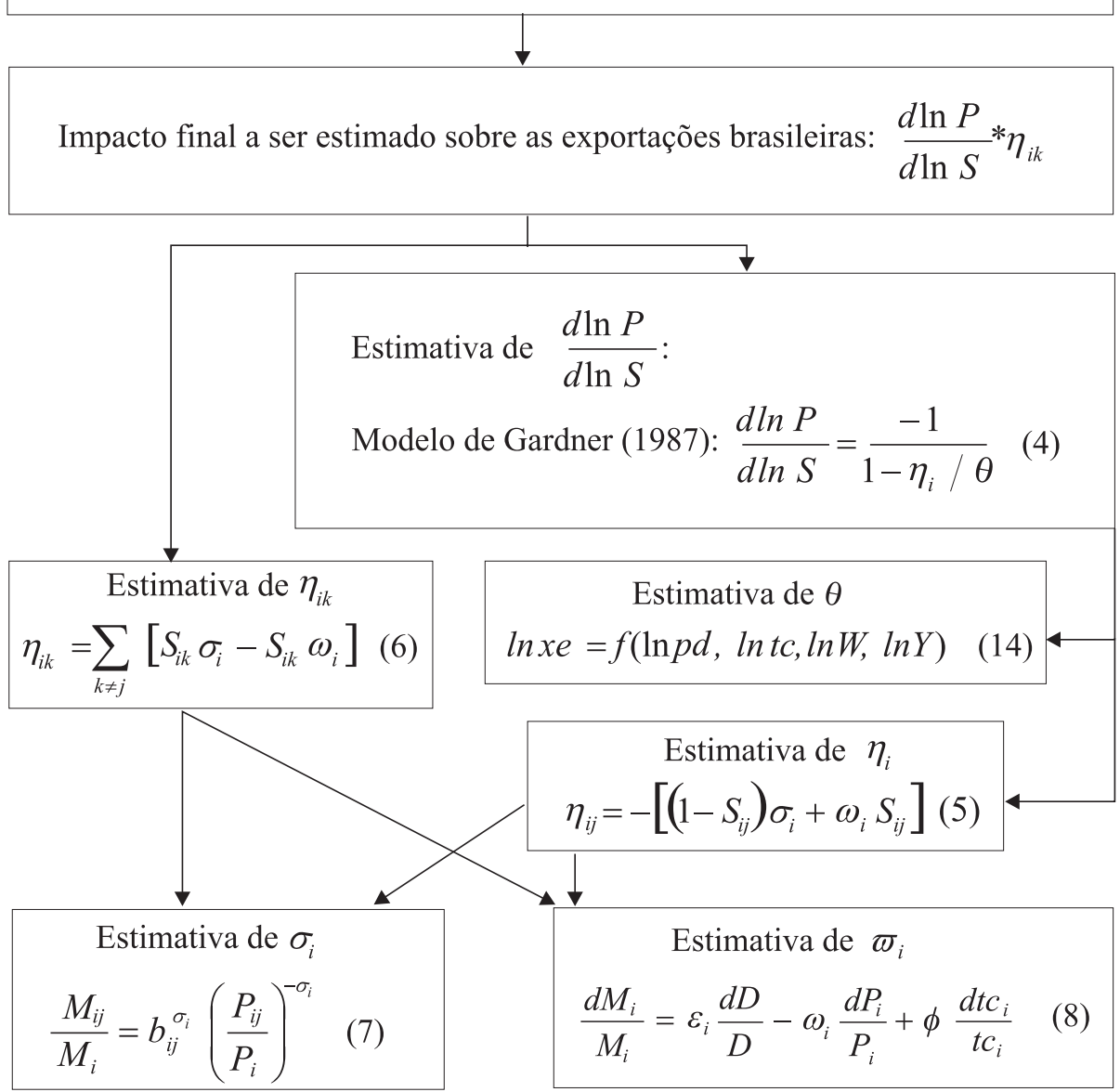

Nota: $d \ln P / d \ln S$ é a variação do preço de exportação da UE em função de uma variação no equivalente subsídio; $\eta_{i k}$ é a elasticidade-preço cruzada de demanda por importação diferenciada por país de origem; $i$ representa os países selecionados que importam açúcar refinado da UE e do Brasil e $k$ representa a UE; $\eta_{i}$ é a elasticidade-preço de demanda diferenciada por país de origem; $\sigma_{i}$ é a elasticidade de substituição; e $\varpi_{i}$ é a elasticidade-preço total de importação; $\theta$ é a elasticidade-preço de oferta de exportação européia.

Para representar esse contexto analítico, definem-se as seguintes equações de oferta e de demanda para um dado país $i$ :

$$
\begin{aligned}
& P_{D}+S=B Q_{S}^{1 / \theta} \\
& P_{D}=A Q_{D}^{1 / \eta_{i}}
\end{aligned}
$$


onde os consumidores pagam o preço de mercado $\left(P_{D}\right)$, e os produtores esperam receber o preço de mercado mais um subsídio, ou seja, $\left(P_{D}+S\right)$. As variáveis $A$ e $B$ são as constantes do modelo; $Q_{S}^{1 / \theta}$ e $Q_{d}^{1 / \eta_{i}}$ são as funções inversas de oferta e de demanda, respectivamente, em que $\theta$ representa a elasticidade-preço de oferta, comum para todos os países demandantes; e $\eta_{i}$ é a elasticidade-preço de demanda para o país $i$. Espera-se que a quantidade ofertada seja positivamente relacionada com o preço $(\theta>0)$, e a elasticidade-preço de demanda tenha sinal negativo $\left(\eta_{i}<0\right)$; ou seja, espera-se uma relação inversa entre a variação no nível de preço de demanda e o volume importado pelo país $i$.

Aplicando logaritmo e diferenciando todos os termos das equações (1) e (2), igualando e rearranjando os termos tem-se:

$$
\frac{d \ln Q}{d \ln S}=\frac{-1}{1 / \eta_{i}-1 / \theta}
$$

A equação (3) descreve o efeito final sobre o volume exportado para o país $i$ quando ocorre uma variação no nível do subsídio (ad valorem) no país exportador. Partindo das hipóteses previamente estabelecidas para as elasticidades-preço de oferta e de demanda $\left(\theta>0\right.$ e $\left.\eta_{i}<0\right)$, espera-se que a elasticidade definida pela equação (3) apresente sinal positivo. Nesse caso, uma redução no nível de subsídio do país exportador provoca uma redução da quantidade comercializada com o país importador.

Para identificar o efeito sobre o preço de demanda $\left(P_{D}\right)$, divide-se o logaritmo da equação (1), ou da equação (2), por $d \ln S$, e substitui-se na equação (3), obtendo-se:

$$
P_{D}
$$

A equação (4) expressa o efeito de uma variação no nível de subsídio do país exportador sobre o preço de oferta da commodity considerada naquele país. Esse efeito será negativo considerando a hipótese de que $\theta>0$ e $d<0$. Isto implica que uma redução no subsídio aumenta o preço de exportação. Se o valor absoluto da elasticidade-preço da oferta for maior do que o da elasticidadepreço da demanda $\eta_{i} \quad$, o efeito da redução do subsídio sobre o preço será tanto maior quanto maior o valor absoluto de $\theta$.

Neste trabalho, buscou-se estimar o efeito de redução no subsídio sobre o preço de exportação do país que subsidia, ou seja, o valor da elasticidade descrita na equação (4). Esse valor é utilizado para estimar o aumento das exportações brasileiras, em razão da redução no subsídio de outros países exportadores que atuam nos mesmos mercados, via efeito-preço cruzado da demanda dos importadores. Estes últimos são selecionados de forma a compor o conjunto com importadores comuns aos referidos países exportadores, no período tomado para a análise.

É importante ressaltar, portanto, que pressuposições simplificadoras foram utilizadas para viabilizar a análise. A primeira pressuposição considera que a expansão da participação brasileira no mercado de açúcar, quando as exportações da UE se retraem, mantém-se restrita aos países nos quais ambos, Brasil e União Européia, atuam simultaneamente como exportadores. Ou seja, assume-se que no caso de ocorrer um corte dos subsídios às exportações da UE, essas se retraem, dando espaço à expansão das exportações brasileiras apenas nos mercados onde o açúcar brasileiro já tem alguma participação. Mais especificamente, não se considerou a possibilidade da exportação 
brasileira vir a se estender para mercados onde, a princípio, apenas a União Européia e outros países - que não o Brasil - tivessem participação.

A segunda considera que a participação das exportações brasileiras cresceria somente em função do aumento do mercado resultante da redução das exportações da UE, não se considerando o efeito de competitividade do Brasil em relação aos demais países ofertantes. Sendo o Brasil altamente competitivo neste mercado, o ganho de comércio poderia ser ainda maior para o Brasil. Ou seja, não se considerou o efeito competitividade, que poderia induzir um aumento ainda mais significativo do market-share brasileiro em outros mercados. Essas pressuposições simplificadoras levam a crer que o aumento das exportações brasileiras captado pela análise pode estar sendo subestimado, sendo este viés tanto maior quanto mais acentuada for a competitividade e a capacidade do país em atuar nos mercados antes ocupados apenas pela UE.

O modelo de Armington (1969) foi utilizado para estimar as elasticidades-preço de demanda. Para estimar a elasticidade-preço de oferta da União Européia foi utilizado um modelo desenvolvido para expressar as características do mercado exportador. Esse modelo considera o excedente de consumo doméstico para explicar as exportações de açúcar da União Européia.

Inicialmente, foram estimadas as equações de demanda de alguns dos países importadores de açúcar refinado, comuns ao Brasil e à UE. A demanda foi estimada com referência às importações da UE, uma vez que se necessita da elasticidade-preço direta $((\mid \theta)$ para compor o modelo de Gardner (1987), e da elasticidade-preço cruzada $\left(\eta_{i j}\right)$ em relação a estas importações.

A teoria de Armington (1969) mostra que a elasticidade preço direta da demanda pela importação originada do país $j$, para o país $i\left(\eta_{i j k}\right)$, pode ser obtida da seguinte maneira:

$$
\eta_{i j}
$$

onde os coeficientes $\eta_{i j}, \sigma_{i}$ e $\omega_{i}$ são, respectivamente, a elasticidade de substituição para o produto demandado, a elasticidade-preço total da demanda e a participação do valor importado do país $j$ em relação ao valor das importações totais do país demandante $(i)$.

A elasticidade-preço cruzada da demanda pela importação originada do país $j$ em relação ao preço do produto do país $k$, no país $i$, é descrita como:

$$
M_{i}
$$

em que $k$ é outro país ofertante do produto considerado para o país $i$.

A elasticidade de substituição pode ser estimada da seguinte maneira:

$$
\eta_{i k}=\sum_{k \neq j}\left[S_{i k} \sigma_{i}-S_{i k}\right.
$$

onde $M_{i j}$ e $M_{l}$ são, respectivamente, o volume e o preço de importação originada de um país $j$ qualquer para o país $i$, do produto considerado; e $M_{i}$ e $P_{i}$ são, respectivamente, o volume e o preço de importação total do produto pelo país i.

A elasticidade-preço de demanda pode ser obtida pela seguinte equação: 
$P_{i j}$

em que $M$ indica quanto as importações do país $i$ são influenciadas pela sua própria taxa de câmbio, e $P_{i}$ representa a elasticidade-renda da demanda pelas importações do país.

O modelo de oferta das exportações de açúcar refinado da UE foi baseado no quantum exportado, definido como sendo o excedente de consumo doméstico do bloco, em que o alto valor do preço do produto é o subsídio recebido pelo produtor para exportar o produto ao nível do preço mundial. Desta maneira, como descrito em Bacchi et al. (2002) e Barros et al. (2002) para o mercado brasileiro, e utilizando o mesmo raciocínio para o mercado europeu, tem-se:

$$
\ln x e=\ln S_{d}-\ln D_{d}
$$

onde $\ln x e$ é o logaritmo do volume ofertado de açúcar pela União Européia; $\ln S_{d}$ é o logaritmo da oferta total de açúcar e $\ln D_{d}$ é o logaritmo da demanda doméstica da UE. As funções de oferta e de demanda doméstica, por sua vez, são definidas na forma logarítmica, como:

$$
\begin{aligned}
& \ln S_{d}=\alpha_{0}+\alpha_{1} \ln p d+\alpha_{2} \ln W \\
& \ln D_{d}=\alpha_{3}+\alpha_{4} \ln p d+\alpha_{5} \ln Y
\end{aligned}
$$

em que pd é o preço doméstico do açúcar da UE. Este preço incorpora o valor do subsídio pago ao produtor, fazendo com que o alto preço recebido no mercado da UE possibilite que este açúcar possa ser exportado ao nível de preço internacional. $W$ é um deslocador da oferta, considerado como o volume importado de açúcar bruto pela UE, uma vez que este açúcar é refinado, podendo ser exportado, em razão do excedente doméstico; e $Y$ é um deslocador da demanda, considerado como a renda doméstica.

Substituindo as equações (10) e (11) na equação (9) obtém-se:

$$
\ln x e=\alpha_{0}+\alpha_{1} \ln p d+\alpha_{2} \ln W-\left(\alpha_{3}+\alpha_{4} \ln p d+\alpha_{5} \ln Y\right)
$$

Portanto, a quantidade ofertada para exportação é uma função de:

$$
\ln x e=f(\ln p d, \ln W, \ln Y)
$$

Sendo $p d$ descrito em moeda estrangeira, espera-se também o efeito da taxa de câmbio sobre as exportações. Assim, tem-se o seguinte modelo para descrever o excedente exportável de açúcar refinado da União Européia:

$$
\ln x e=f(\ln p d, \ln t c, \ln W, \ln Y)
$$

Do modelo descrito em (14), espera-se uma relação positiva entre a quantidade exportada com seu preço $(p d)$, com o volume importado de açúcar bruto $(W)$ e com a taxa de câmbio $(t c)$. Para a variável renda, espera-se uma relação negativa, por aumentar a demanda interna reduzindo 
o excedente exportável. Entretanto, a taxa de câmbio e a renda são variáveis que afetam, também, o volume importado de açúcar bruto. Esperam-se, porém, sinais contrários aos descritos para as exportações de açúcar refinado. Desta maneira, aqueles coeficientes foram avaliados considerando sua significância no modelo, para definir sua inclusão ou não na estimação do modelo.

O coeficiente estimado para a variável $\ln p d$ fornece, diretamente, o valor da elasticidade de oferta da exportação de açúcar refinado da União Européia. O valor dessa elasticidade será utilizado nas equações (3) e (4), de maneira que, juntamente com a estimativa da elasticidade da demanda, se obtenha: pela equação (3), as estimativas do efeito final sobre o volume exportado para o país $i$, quando ocorre um choque no nível de subsídio (ad valorem) da UE; e pela equação (4), o efeito final sobre o preço de exportação da UE quando ocorre uma variação no nível de subsídio.

\subsection{Fonte de dados}

Para estimar as equações de demanda por importação de açúcar refinado nos países selecionados, que importam tanto do Brasil quanto da UE, foram utilizados: os volumes e valores (para calcular o preço de importação de açúcar refinado) de importação na FAO (2003) e United Nations (2003); volumes e valores da importação de açúcar desses países originado da União Européia (obtidos na European Commission, 1998, 2000); foram utilizadas as taxas de câmbio efetiva real, ou, para os países que não dispunham deste dado, foram utilizados valores da taxa de câmbio nominal, transformada em índice, deflacionados pelo índice de preços ao consumidor daqueles países. Os dados foram obtidos no International Monetary Fund - IMF (2000); como proxy da renda utilizouse o valor das importações totais dos países, obtidos no IMF (2000).

Para estimar a função de exportação de açúcar bruto da União Européia, o volume de açúcar refinado exportado extrabloco foi obtido na European Commission (1998 e 2000). Para calcular o preço recebido pelos exportadores de açúcar foi utilizado o preço de exportação intrabloco, dividindo os dados do valor pelo volume exportado obtidos na European Commission (1998 e 2000). A taxa de câmbio foi obtida no IMF (2000); e como proxy da renda foi utilizado o valor total das importações, obtidos no IMF (2000).

Deve-se ressaltar que as variáveis foram utilizadas em logaritmos, de modo a obter diretamente os valores das elasticidades desejados.

\section{RESUlTAdos E DisCUSSÃO}

Neste item, os resultados das estimativas dos modelos apresentados acima são discutidos, apresentando-se, inicialmente, a elasticidade-preço direta e cruzada da demanda. A seguir, a elasticidade-preço de oferta da UE é apresentada. Finalmente, calcula-se o impacto da redução do subsídio sobre o nível de preço do açúcar exportado pela UE e os impactos sobre o volume exportado da UE e do Brasil.

\subsection{Funções de demanda pela importação de açúcar refinado da União Européia - países selecio- nados}

O primeiro desafio foi identificar os países que apresentassem, ao mesmo tempo, uma participação significativa nas exportações de açúcar refinado da UE, e que fossem importadores de açúcar brasileiro no período da análise. Os países selecionados para a estimação das elasticidades-preço 
direta e preço cruzada de demanda pelas importações de açúcar refinado originadas da UE são apresentados na Tabela 1.

Tabela 1 - Participação do valor das importações originadas da UE e do Brasil em relação à importação total de açúcar refinado nos países selecionados $\left(S_{i j}\right)$, no período de 1996 a 1999 e participação geral no período de 1989 a 1999

\begin{tabular}{lccc}
\hline & $\begin{array}{c}\text { Importações originadas } \\
\text { da UE }\end{array}$ & $\begin{array}{c}\text { Importações originadas } \\
\text { do Brasil }\end{array}$ & $\begin{array}{c}\text { Importações originadas da UE } \\
\text { e do Brasil }\end{array}$ \\
\hline Argélia & $51 \%$ & $24 \%$ & $75 \%$ \\
Arábia Saudita & $18 \%$ & $4 \%$ & $22 \%$ \\
Costa do Marfim & $54 \%$ & $3 \%$ & $57 \%$ \\
Egito & $24 \%$ & $47 \%$ & $71 \%$ \\
Emirados Árabes & $74 \%$ & $3 \%^{*}$ & $74 \%$ \\
Gâmbia & $15 \%$ & $51 \%$ & $66 \%$ \\
Gana & $26 \%$ & $67 \%$ & $93 \%$ \\
Índia & $23 \%$ & $30 \%$ & $53 \%$ \\
Indonésia & $5 \%$ & $7 \%$ & $12 \%$ \\
Irã & $42 \%$ & $10 \%{ }^{*}$ & $42 \%$ \\
Israel & $83 \%$ & $0 \%$ & $83 \%$ \\
Jordânia & $29 \%$ & $32 \%$ & $61 \%$ \\
Nigéria & $8 \%$ & $45 \%$ & $53 \%$ \\
Serra Leoa & $66 \%$ & $7 \%{ }^{*}$ & $66 \%$ \\
Síria & $73 \%$ & $2 \%{ }^{*}$ & $73 \%$ \\
Sri Lanka & $9 \%$ & $31 \%$ & $40 \%$ \\
Tunísia & $73 \%$ & $10 \%$ & $83 \%$ \\
Turquia & $65 \%$ & $0 \%$ & $65 \%$ \\
lêmen & $8 \%$ & $26 \%{ }^{*}$ & $8 \%$ \\
Participação do valor importado originado da UE na importação total dos países & & $37 \%$ \\
\hline
\end{tabular}

* Participações calculadas nos dados de exportação brasileira em Brasil (2005) e importação total do país pela FAO (2005). Demais participações calculadas pelo Comtrade (2005) e European Commission (1998, 2000).

Fonte: Comtrade (2005); European Commission (1998, 2000); (Brasil, 2005); (FAO, 2005).

A Tabela 1 apresenta os países selecionados, e as respectivas participações $\left(S_{i j}\right)$ das importações da UE em relação à importação total de açúcar refinado realizadas por esses países. Os países listados foram responsáveis por um total médio de $42 \%$ do valor das exportações extrabloco da UE, realizadas no período de 1989 a 1999.

Em seguida, foram estimadas as equações de elasticidade de substituição e de elasticidade de demanda total pelas importações de açúcar refinado para os países selecionados. Tais modelos estão descritos no modelo de demanda de Armington no item Metodologia (item 2). Estimou-se um único valor de elasticidade de substituição e de elasticidade de demanda para todos os países considerados. O mesmo se aplica à elasticidade-preço direta em relação à demanda pelas importações européias. Foi estimado um único valor destas elasticidades porque elas foram utilizadas para estimar o efeito da redução do subsídio na UE sobre o nível de preço do açúcar comercializado com este bloco e, provavelmente, este efeito ocorrerá considerando o conjunto de países que demandam o produto da UE. Para estimar a elasticidade-preço direta da demanda utilizou-se como valor do $S_{i j}$ 
a participação geral das importações européias em todos os países considerados, descrita na última linha da Tabela 1.

A estimação foi realizada utilizando dados em painel, onde os países foram descritos com os dados cross-section, e os dados de séries temporais foram considerados para o período de 1989 a 1999. O método de estimação de dados em painel que melhor se ajustou às equações estimadas foi o de Fuller e Battese. Este método decompõe os erros da regressão em três diferentes componentes: (i) erro proveniente do componente cross-section; (ii) erro do componente temporal e (iii) erro da série como um todo. Assim, a matriz de covariância utilizada para estimar os parâmetros do modelo pelo método de mínimos quadrados generalizados é composta pela soma das três matrizes de covariância separadamente.

Os coeficientes estão descritos na Tabela 2, onde os valores entre parênteses abaixo dos coeficientes indicam os respectivos níveis de significância do teste " $\mathrm{t}$ ".

Os sinais dos coeficientes obtidos e descritos na Tabela 2 apresentaram-se de acordo com o esperado pelo modelo econômico. A elasticidade-preço de substituição dos países importadores de açúcar refinado foi elástica (elasticidade maior do que 1), e a elasticidade-preço da importação geral de açúcar refinado apresentou-se inelástica. Isso indica que os países importadores reduzem a importação de açúcar em proporção menor do que o aumento do preço. No entanto, existe uma relativa facilidade em substituir a origem do açúcar importado (elasticidade de substituição maior do que 1), indicando mercado relativamente competitivo.

Tabela 2 - Estimativas das elasticidades-preço de substituição e de demanda da importação de açúcar refinado para países selecionados, importadores da União Européia e do Brasil; período de 1989 a 1999

\begin{tabular}{lcccccc}
\hline & Intercepto & $\ln \left(P_{i j} / P_{i}\right)$ & $\ln P i$ & $\operatorname{lntc}$ & lnren & $\mathrm{R}^{2}$ \\
\hline $\ln \left(M_{i j} / M_{i}\right)$ & $-1,35$ & $-1,06$ & - & - & - & $4 \%$ \\
Volume importado $\left(\ln M_{i}\right)$ & $(0,00)$ & $(0,00)$ & - & - & - & \\
& 11,70 & - & $-0,63$ & $-0,30$ & 0,53 & $11 \%$ \\
& $(0,00)$ & - & $(0,04)$ & $(0,33)$ & $(0,00)$ & \\
\hline
\end{tabular}

Nota: $\ln \left(M_{i j} / M_{i}\right)=$ Logaritmo da participação das importações originadas do país $j$ nas importações totais do país $i ; \ln \left(P_{i j} / P_{i}\right)$ $=$ Logaritmo da relação entre o preço de importação do país $j$ no preço geral da importação do país $i ; \ln M_{i}=$ Logaritmo do volume total importado de açúcar; $\ln P i=\log$ aritmo do preço de importação de açúcar refinado; $\operatorname{lntc}=\log$ aritmo do índice taxa de câmbio efetiva real; lnren = logaritmo da variável valor da importação total, utilizada como proxy para estimar o efeito renda.

Os coeficientes estimados indicam que um aumento de $1 \%$ no preço de importação de açúcar refinado reduziria o volume demandado do produto em $0,63 \%$. Para a taxa de câmbio, a elasticidade resultou em aproximadamente $0,3 \%$, porém não foi significativa. A renda foi outro fator importante na determinação da importação de açúcar refinado pelos países considerados para a análise (descritos na Tabela 1). Provavelmente, isso ocorreu porque esses países são, em sua maioria, classificados como países menos desenvolvidos, nos quais o fator renda é determinante para o consumo, mesmo para os alimentos considerados básicos.

Os valores das elasticidades de substituição e de preço descritos na Tabela 2 foram utilizados para estimar os valores das elasticidades-preço direta e cruzada do açúcar importado. A elasticidade-preço cruzada da demanda foi estimada considerando um valor por país importador de açúcar 
refinado da UE. Isto se justifica, porquanto o valor desta elasticidade interfere no volume de açúcar exportado pelo Brasil. Além disso, em razão dos diferentes valores destas elasticidades, tem-se também, de maneira distinta, o impacto sobre as exportações brasileiras, para cada um dos países selecionados. Nesta etapa, foi importante determinar a participação das exportações brasileiras para os países selecionados, porque o impacto sobre as mesmas foi estimado tendo-se como base as exportações verificadas para aqueles mercados.

Como a desregulamentação das exportações brasileiras de açúcar foi promovida no início da década de 1990, o aumento dessas exportações, em razão da redução nas barreiras protecionistas, é melhor visualizado a partir das exportações de 1996, quando se considera que o impacto da desregulamentação já estaria neutralizado. Considerando-se ainda que neste item as exportações da UE também foram utilizadas, e os dados disponíveis estendiam-se até 1999, procedeu-se à padronização por um período base, os anos de 1996 a 1999, para estimar o impacto nas exportações brasileiras e européias. Considerando o período base escolhido, as exportações para os países selecionados totalizaram $44 \%$ do valor das exportações européias extrabloco e $74 \%$ do valor das exportações brasileiras totais de açúcar refinado (sendo $63 \%$ originárias do Centro-Sul e $11 \%$ do Norte-Nordeste). Os valores da elasticidade-preço direta e das elasticidades-preço cruzadas, utilizadas para as estimações do próximo item, estão descritos na Tabela 3. Os modelos empregados para o cálculo dos valores dessas elasticidades estão descritos nas equações (5) e (6), respectivamente para as elasticidade-preço direta e elasticidade-preço cruzada.

Tabela 3 - Estimativa da elasticidade-preço direta $\left(\eta_{i j}\right)$ e preço cruzada $\left(\eta_{i j k}\right)$ da demanda pela importação de açúcar refinado da União Européia para cada um dos países selecionados

\begin{tabular}{lllllc}
\hline País importador & $\eta_{j k}$ & \multicolumn{1}{c}{ País importador } & $\eta_{j k}$ & País importador & $\eta_{j k}$ \\
\hline Argélia & 0,87 & Gana & 0,44 & Nigéria & 0,13 \\
Arábia Saudita & 0,30 & Índia & 0,38 & Serra Leoa & 1,12 \\
Costa do Marfim & 0,92 & Indonésia & 0,09 & Síria & 1,23 \\
Egito & 0,41 & Irã & 0,71 & Sri Lanka & 0,16 \\
Emirados Árabes & 1,26 & Israel & 1,40 & Tunísia & 1,23 \\
Gâmbia & 0,25 & Jordânia & 0,50 & Turquia & 1,11 \\
& & & & lêmen & 0,13 \\
\hline \multicolumn{2}{l}{ Elasticidade-preço direta $\left(\eta_{i j}\right)$} & & & $-0,90$ \\
\hline
\end{tabular}

Verifica-se na Tabela 3 que a elasticidade de demanda pela importação de açúcar refinado da UE foi de 0,9 . Ou seja, um aumento de $1 \%$ no preço de oferta da UE, ocasionado por redução dos subsídios ao produtor doméstico, reduziria a quantidade demandada pelo açúcar europeu em 0,9\%.

Em relação à elasticidade-preço cruzada, os valores devem ser interpretados da seguinte maneira: um aumento de $1 \%$ do preço de oferta de açúcar refinado da UE aumenta a demanda de um outro país ofertante em $\eta_{i j k}(\%)$ no país importador considerado. No caso desta análise, verificou-se o impacto desse aumento de preços na oferta da UE sobre a demanda pela importação de açúcar refinado do Brasil.

Dentre os países selecionados, aqueles que aumentariam a importação de outros países de maneira mais do que proporcional ao aumento de preço do açúcar europeu foram identificados como os Emirados Árabes, Israel, Serra Leoa, Síria, Tunísia e Turquia. Isso se deve ao fato de que nesses países mais de $60 \%$ do valor importado de açúcar refinado foi originário da UE, e no caso de aumento de preço deste ofertante, o deslocamento da importação seria, conseqüentemente, maior. 
Os resultados das elasticidades descritas na Tabela 3 foram utilizados no próximo item, quando foram estimados os impactos da redução dos subsídios na UE.

\subsection{Oferta das exportações de açúcar refinado pela União Européia}

Estudo realizado por Frandsen et al. (2001) encontraram que: França, Alemanha, Áustria e Reino Unido são capazes de produzir açúcar para o mercado mundial (quota C); Dinamarca, Bélgica e Espanha podem abastecer as quotas nacionais; o custo de produção na Suécia, Holanda e Irlanda podem impedi-los de utilizar a quota B; e que Itália, Finlândia e, notavelmente, Portugal e Grécia poderiam ter dificuldades em produzir a quota A. Esses resultados foram obtidos com base nos custos de produção desses países.

Diante dessas informações indicando a diferenciação entre os países da UE, foi realizado um estudo preliminar com o objetivo de identificar os fatores determinantes do comércio de açúcar nesses países. Observou-se a presença de dois tipos de países, em relação ao mercado de açúcar. Num primeiro grupo de países, a importação de açúcar bruto mostrou-se relacionada à produção doméstica, ou seja, os países importaram mais quando a produção doméstica reduziu. Esses países não foram exportadores de açúcar refinado. Desta maneira, a importação de açúcar teve o objetivo de complementar a produção para o consumo doméstico. Os países que apresentaram este comportamento foram: Portugal, Grécia, Itália, Finlândia, Irlanda e Suécia. A correlação entre importação de açúcar bruto e a produção doméstica de açúcar bruto foi de $-38 \%$ para esses países. O segundo grupo compreendeu exportadores mundiais de açúcar refinado, que importaram açúcar bruto extrabloco em razão de condições favoráveis àquelas importações, para reexportá-lo como refinado. Pertencem a este grupo de países: França, Alemanha, Reino Unido, Áustria, Dinamarca, BélgicaLuxemburgo, Espanha e Holanda. Estes resultados corroboram os encontrados por Frandsen et al. (2001), uma vez que os países descritos por estes autores como incapazes de produzir as quotas B e mesmo a quota A correspondem aos descritos no primeiro grupo de países. Da mesma forma, os países do segundo grupo foram aqueles descritos pelos autores como capazes de produzir para o mercado mundial ou de abastecer as quotas nacionais. Entre os países descritos por Frandsen et al. (2001) como podendo ser incapazes de produzir a quota B, apenas Holanda apresentou-se como exportadora de açúcar refinado, sendo incluída no segundo grupo dos países da UE.

Nos países exportadores de açúcar refinado não foi observada uma relação negativa entre a produção doméstica e a importação de açúcar bruto (o valor da correlação foi de 0,08). Entretanto, observou-se correlação de $77 \%$ entre as exportações de açúcar refinado com a produção doméstica, para o período de 1989 a 1999.

A função de oferta de exportação de açúcar refinado foi estimada para este segundo grupo de países, que possuem excedente de oferta e ainda assim importaram açúcar bruto. O modelo proposto para esta equação foi discutido na Metodologia, descrita no item 2 do presente trabalho. Para estimar a função de oferta da exportação de açúcar refinado, como uma aproximação do preço recebido pelo produtor da UE pelas exportações extrabloco, foi utilizado o preço das exportações intrabloco do produto. O preço de exportação de açúcar refinado intrabloco foi utilizado porque os produtores exportam tanto intra quanto extrabloco. Entretanto, em virtude dos maiores preços intrabloco recebidos (quota A) é que o produtor terá estímulo para aumentar sua produção e, conseqüentemente, seu excedente exportável para o mercado externo. A Tabela 4 descreve os coeficientes obtidos na estimação da equação de oferta das exportações de açúcar refinado da UE. A equação foi estimada utilizando dados em painel, onde os países da UE considerados foram os dados crosssection e a série temporal consistiu de dados do período de 1989 a 1999. Os coeficientes foram esti- 
mados pelo método de Parks, que apresentou melhor ajustamento para esta equação. Utilizou-se o método de Parks quando a estrutura do termo de erro do modelo apresenta heteroscedastícia, indicando ser contemporaneamente correlacionado, tendo estrutura auto-regressiva. A matriz de covariância utilizada para a estimação pelo método de mínimos quadrados generalizados leva em consideração essa estrutura do erro, de modo que os parâmetros estimados são consistentes.

Tabela 4 - Estimativas das elasticidades de oferta das exportações de açúcar refinado da União Européia; período de 1989 a 1999

\begin{tabular}{lcccc}
\hline & Intercepto & $\operatorname{lnp} d r$ & $\ln t c$ & $\ln M i$ \\
\hline Volume exportado $($ lnxe) & 17,09 & 0,26 & $-1,11$ & 0,15 \\
$\mathrm{R}^{2}=47 \%$ & $(0,00)$ & $(0,00)$ & $(0,02)$ & $(0,00)$ \\
\hline
\end{tabular}

Nota: em que lnxe é o logaritmo do volume exportado extrabloco de açúcar refinado; lnpdr é o logaritmo do preço de exportação intrabloco de açúcar refinado da União Européia; lntc é o logaritmo do índice da taxa de câmbio (efetiva real) dos países; e $\ln M i$ é o logaritmo do volume importado extrabloco de açúcar bruto.

Como demonstrado, as exportações de açúcar refinado estiveram relacionadas com as importações de açúcar bruto. Este fato pode estar influenciando o sinal negativo do coeficiente da taxa de câmbio no modelo de oferta. Isto ocorre porque a redução da taxa de câmbio favorece as importações de açúcar, que pode então ser reexportado. Acredita-se que o sinal desta variável apresentou-se contraditório justamente pela característica ambígua que ela representa para o mercado de açúcar nestes países: do mesmo modo que a taxa de câmbio, a variável renda também influenciaria de maneira contrária a importação e a exportação de açúcar. A inclusão do volume importado de açúcar bruto, portanto, foi importante para a estimação correta deste modelo.

A Tabela 4 mostra como fatores importantes e estatisticamente significativos para explicar a oferta de exportação de açúcar refinado da UE: (i) o estímulo do preço recebido pelo produtor no mercado interno do bloco, com elasticidade estimada de $0,26 \%$ e (ii) o estímulo para a importação do açúcar bruto, cuja elasticidade foi estimada em 0,15\%. O baixo valor da elasticidade-preço de oferta pode ser explicado pelo fato de o nível de subsídio da UE apresentar-se tão elevado que uma redução marginal não seria capaz de provocar reduções expressivas na oferta do produto.

\subsection{Impacto da redução do subsídio da União Européia sobre as exportações de açúcar refinado do bloco europeu e do Brasil}

Neste item a análise foi conduzida da seguinte maneira: (i) foi estimado o modelo descrito por Gardner (1987) para verificar o efeito de redução no subsídio concedido aos produtores da UE sobre volume e preço de suas exportações; (ii) com base nos resultados obtidos no item (i) em relação ao efeito sobre o nível de preço, e na estimativa da elasticidade-preço cruzada das exportações da UE obtidas anteriormente (Tabela 3), obteve-se o efeito estimado sobre o volume das exportações brasileiras (desagregadas em Centro-Sul e Norte-Nordeste).

O modelo de Gardner (1987) identificou os possíveis efeitos da redução nos subsídios (considerado aqui como subsídio cruzado) da UE sobre o comércio de açúcar refinado com os países demandantes considerados. Os resultados obtidos da aplicação das equações (3) e (4) do modelo utilizado estão descritos na Tabela 5. 
Os resultados do modelo de Gardner (1987), estimados para verificar o efeito sobre volume e preço comercializado da UE com os países demandantes selecionados, indicaram que a redução de $1 \%$ no nível do subsídio da UE $(d S)$ diminuiria em $0,20 \%$ a quantidade demandada de açúcar refinado, e aumentaria o preço de exportação do açúcar europeu em 0,22\%.

Tabela 5 - Estimativas das mudanças porcentuais em volume e preço das exportações européias de açúcar refinado em razão de mudanças nos níveis de subsídios concedidos

\begin{tabular}{lcccc}
\hline & Elasticidade-preço de oferta & $\begin{array}{c}\text { Elasticidade-preço de } \\
\text { demanda }\end{array}$ & $d Q / d S$ & $d P / d S$ \\
\hline Exportação da União Européia & 0,26 & $-0,90$ & 0,20 & $-0,22$ \\
\hline
\end{tabular}

Nota: $d Q / d S$ = variação da quantidade exportada em função de uma variação no equivalente subsídio; $d P / d S$ = variação do preço de exportação em função de uma variação no equivalente subsídio.

A Tabela 5 apresentou os resultados obtidos para identificar o impacto da redução de subsídio na UE sobre as próprias exportações européias. Na Tabela 6 estão descritos os impactos estimados da redução de $1 \%$ de subsídio na UE sobre o aumento das exportações brasileiras. Para isto foi utilizado apenas o impacto sobre o nível de preço $(d P / d S)$. Isto ocorre porque o valor da elasticidade-preço cruzada da demanda é a ligação existente entre o efeito da redução do subsídio na UE com as exportações brasileiras de açúcar refinado. Os valores constantes da Tabela 6 descrevem o aumento porcentual da demanda nos países selecionados. Este efeito foi estimado multiplicando a elasticidade de variação do preço de exportação em função de uma variação no equivalente subsídio $(d P / d S=-0,22)$, descrita na Tabela 5, pela elasticidade-preço cruzada da demanda de outros países em relação ao preço da UE, descrita na Tabela 3.

Os impactos estimados na Tabela 6 não são distintos segundo a origem das importações. Para identificar o impacto do aumento das exportações de cada fornecedor de açúcar para aqueles países considerou-se a participação das exportações já existentes, conforme as pressuposições simplificadoras explicitadas anteriormente na Metodologia. Assim, multiplicando os resultados da Tabela 6 pelas exportações de açúcar refinado das duas regiões brasileiras verificou-se que a região CentroSul aumentaria em 1.309 toneladas suas exportações e o Norte-Nordeste em 205 toneladas, com destino aos países selecionados. Entretanto, a diferença do impacto em relação às regiões CentroSul e Norte-Nordeste decorre apenas da média de suas exportações no período de 1996 a 1999 para os mercados de destino selecionados, uma vez que a elasticidade é a mesma.

Tabela 6 - Impactos estimados sobre a demanda pelas exportações de açúcar refinado, em razão da redução de $1 \%$ no nível de subsídio cruzado as exportações de açúcar refinado na União Européia

\begin{tabular}{lclclc}
\hline País importador & $\%$ & País importador & $\%$ & País importador & $\%$ \\
\hline Argélia & $0,19 \%$ & Gana & $0,10 \%$ & Nigéria & $0,03 \%$ \\
Arábia Saudita & $0,07 \%$ & Índia & $0,08 \%$ & Serra Leoa & $0,25 \%$ \\
Costa do Marfim & $0,20 \%$ & Indonésia & $0,02 \%$ & Síria & $0,27 \%$ \\
Egito & $0,09 \%$ & Irã & $0,16 \%$ & Sri Lanka & $0,03 \%$ \\
Emirados Árabes & $0,28 \%$ & Israel & $0,31 \%$ & Tunísia & $0,27 \%$ \\
Gâmbia & $0,05 \%$ & Jordânia & $0,11 \%$ & Turquia & $0,24 \%$ \\
& & & & lêmen & $0,03 \%$ \\
\hline
\end{tabular}

Os países que aumentariam a demanda pelas importações de açúcar refinado do Centro-Sul do Brasil em um volume superior a 100 toneladas seriam Egito, Jordânia, Nigéria, Argélia e Índia. 
A demanda pelas importações do Norte-Nordeste, mais tímida, seria mais significativa para Argélia, Nigéria, Tunísia, Gana e Irã.

A seguir, foi estimado o nível total de subsídio do mercado europeu. Calculou-se, então, um equivalente subsídio, em termos porcentuais, em relação ao preço que a UE exporta extrabloco. Para isto, foram considerados os preços médios de exportação praticados intra e extrabloco, no período de 1989 a 2001, segundo dados da FAO (2003). A diferença entre esses preços foi da ordem de $139 \%$ do preço extrabloco, que é o preço concorrente com o do mercado mundial do produto. Assim sendo, foi considerada esta diferença como o nível total de subsídio no mercado europeu e, havendo uma redução total no mesmo, a demanda pelo açúcar do Brasil, nos países selecionados, seria significativamente maior, conforme mostrado na Figura 3.

Figura 3 - Impactos estimados sobre a demanda pelas exportações de açúcar refinado nas duas regiões brasileiras, em razão da redução total nos atuais níveis de subsídio cruzado as exportações de açúcar refinado na União Européia ${ }^{4}$

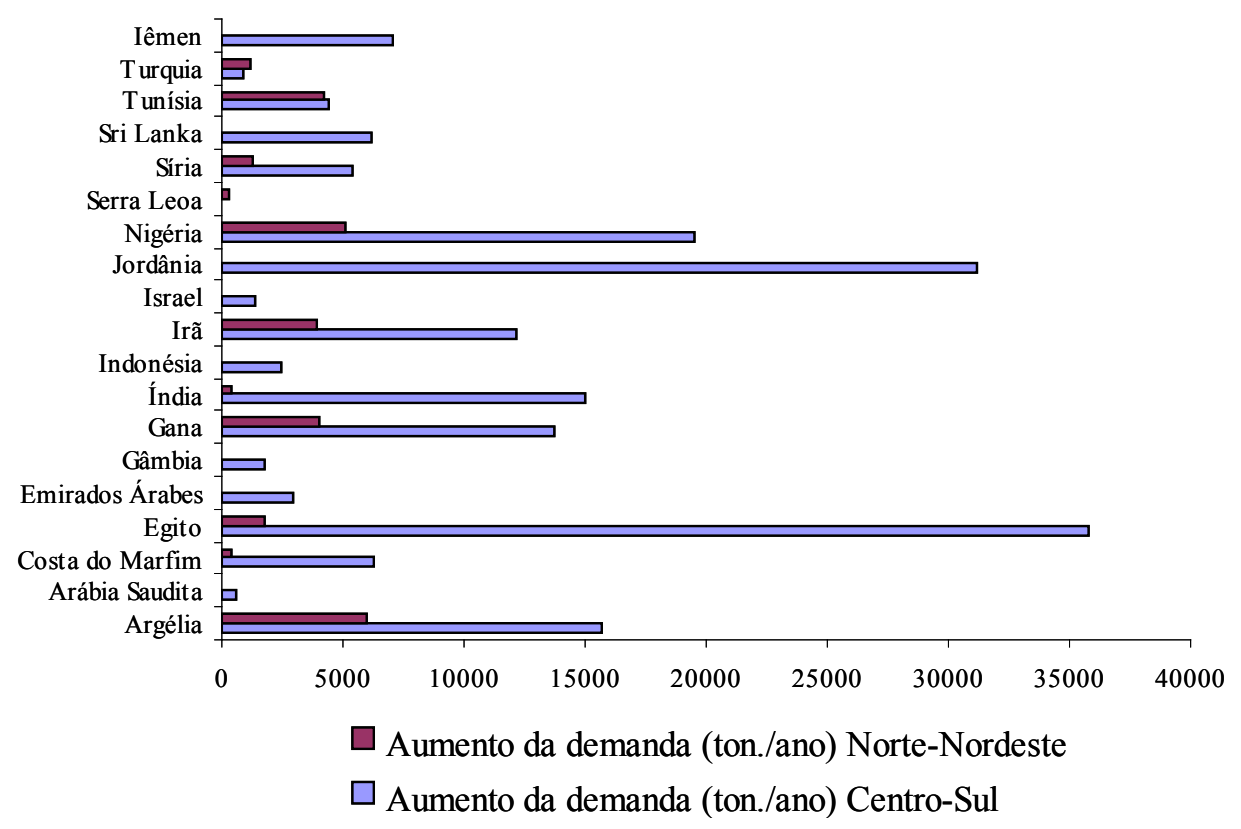

Verifica-se, na Figura 3, que se o Brasil suprir todo o aumento de demanda estimado, as exportações brasileiras deste produto aumentariam em cerca de 211 mil toneladas (182 mil toneladas do Centro-Sul e 29 mil toneladas do Norte-Nordeste). Em relação ao atual nível da exportação existente (considerando a média do período de 1996 a 1999), o aumento estimado, apenas para os 19 países selecionados, representa 7,7\% das exportações brasileiras (6,6\% das exportações do CentroSul e $1 \%$ do Norte-Nordeste). Considerando apenas as exportações daquelas regiões, este aumento correspondeu a 9,5\% das exportações do Norte-Nordeste no período, e 7,4\% das exportações do Centro-Sul.

4 Conforme já descrito, tais níveis de subsídios foram estimados pela autora como sendo a diferença entre o preço intrabloco da UE e o preço internacional de açúcar refinado. 


\section{Conclusões}

Os argumentos apresentados pela União Européia nas negociações com a OMC interpretam as políticas de subsídios como políticas sociais, e não comerciais. No entanto, este trabalho mostra que os subsídios têm impactos expressivos sobre o comércio mundial. Os resultados obtidos destacam a importância de se avaliar os efeitos das políticas de subsídios aplicadas pelos países desenvolvidos sobre os menos desenvolvidos.

Uma limitação do procedimento aplicado para a análise refere-se aos países selecionados para estimar o efeito de eliminação dos subsídios cruzados sobre as exportações de açúcar refinado da União Européia. Acredita-se que esse efeito sobre as exportações brasileiras seria ainda maior do que o estimado, uma vez que se restringiu o número de países importadores potencialmente afetados pela eliminação dos subsídios. Muitos autores demonstram, ainda, que a eliminação desta política poderia aumentar o preço internacional do produto, o que também não foi considerado, mesmo porque essa proposição ainda causa polêmica entre os pesquisadores do assunto. Desta forma, conclui-se que a importância dos subsídios cruzados para as exportações de açúcar pela União Européia poderia ser ainda maior para a economia brasileira. Portanto, parecem existir argumentos sustentados para que o governo brasileiro venha a recorrer na OMC, com pedidos contra tais políticas, à semelhança do que foi realizado, com êxito, no caso do subsídio ao açúcar na União Européia.

Outra conclusão deste trabalho diz respeito à importância da análise regionalizada dos impactos na economia brasileira. Sendo um país de dimensão continental, e possuindo diferenças significativas nas tecnologias e comportamento entre regiões produtoras e exportadoras de um determinado produto, a análise regional dos impactos causados pela redução dos subsídios na UE mostrou-se importante. Verificou-se, neste estudo, um impacto menor na região Norte-Nordeste do Brasil do que na região Centro-Sul. Este resultado já seria esperado considerando as características das duas regiões exportadoras descritas anteriormente.

É importante destacar, ainda, que tais mudanças devem-se aos impactos diferenciados para a atividade na economia brasileira, particularmente quando se considera que duas das mais importantes regiões produtoras de cana, matéria-prima do açúcar, apresentam realidades econômicas e sociais bastante diferenciadas: o Centro-Sul e o Norte-Nordeste. Neste último, a importância relativa do setor é maior, de modo que um impacto positivo pode resultar em estímulos mais importantes que para a região Centro-Sul. Sendo a região Norte-Nordeste caracterizada pela concentração de um grande contingente de população pobre no país, um aumento na demanda pelo açúcar da região deve apresentar um resultado positivo relativamente mais acentuado e favorável em termos de geração de renda e emprego. Esse impacto pode ser um contraponto ao argumento apresentado pela EU, que apresenta a política de subsídio como uma política social. No entanto, é preciso estimar tais impactos para obter conclusões definitivas sobre a questão.

5 A Organização Mundial do Comércio confirmou, no dia 28/04/2005, a vitória do Brasil, Austrália e Tailândia contra os subsídios dados pela União Européia a seus produtores e exportadores de açúcar. (Valor Econômico, 29/04/2005). 


\section{REFERÊNCIAS BIBLIOGRÁFICAS}

Armington, P. S. A theory of demand for products distinguished by place of production. International Monetary Fund Staff Papers, v. 16, n. 1, p. 159-178, 1969.

Australian. Department of Foreign Affairs and Trade. http://www.dfat.gov.au/trade/negotiations/disputes/265_appeal_australias_cross_280105.html\#_ftn56\#_ftn56 (04 abr. 2005)

Bacchi, M. R. P.; Alves, L. R. A.; Silveira, A. M. Exportações brasileiras de açúcar: um modelo de autoregressão vetorial (compact disc). In: Congresso Brasileiro de Economia e Sociologia Rural, 40, Passo Fundo, 2002. Anais. Brasília: SOBER, 2002.

Barros, G. S. C.; Bacchi, M. R. P.; Burnquist, H. L. Estimação de equações de oferta de exportação de produtos agropecuários para o Brasil (1992/2000). Rio de Janeiro: IPEA, 2002. 51p. (Texto para Discussão, 865)

Brasil. Ministério de Agricultura, Pecuária e Abastecimento. Exportações brasileiras de açúcar. http://www. agricultura.gov.br/pls/portal/docs/PAGE/MAPA/ESTATISTICAS/COMERCIO_EXTERIOR_BRASILEIRO/PRINCIPAIS_PRODUTOS/ACUCAR_2002_01_PTB.PDF (12 abr. 2003a)

Brasil. Ministério do Desenvolvimento, Indústria e Comércio Exterior. Alice Web. http://aliceweb.desenvolvimento.gov.br/alice.asp (12 out. 2002 - 13 set. 2003b).

Burnquist, H. L., Bacchi, M. R. P. Análise de barreiras protecionistas no mercado de açúcar. In: Moraes, M. A. F. D.; Shikida, P. F. A. (orgs.), Agroindústria canavieira no Brasil: evolução, desenvolvimento e desafios. São Paulo: Atlas, 2002.

Colsera, L. L. Algodão: as implicações dos subsídios americanos para a produção brasileira. Revista de Política Agrícola, v. 11, n. 3, p. 47-59, jul./ago./set. 2002.

Costa, C. C.; Burnquist, H. L. Análise do desempenho das regiões exportadoras de açúcar e dos tipos de açúcar exportados, no Brasil, após a desregulamentação do setor sucroalcooleiro (compact disc). In: Congresso Brasileiro de Economia e Sociologia Rural, 41. Juiz de Fora, 2003. Anais. Brasília: SOBER, 2003.

European Commission. Internal and external trade of the EU: statistical office of the European Communities (compact disc). Luxembourg: COMEXT, s2/1998.

. Internal and external trade of the EU: statistical office of the European Communities (compact disc). Luxembourg: COMEXT, n.3/2000.

FAO. FAOSTAT agriculture: agriculture \& food trade: crops \& livestock primary \& processed. http://apps. fao.org/page/collections (10 Oct. 2002 - 20 Sep. 2003)

Frandsen, S. E.; Jensen, G. G.; Walter-Jorgensen, W. Y. A. Modelling the EU sugar policy: a study of policy reform scenarios. /Presented to 77. EAAE Seminar; 325. NJF Seminar, Helsinki, Aug. 2001/ http:// www.ptt.fi/eaae-njf/ (23 Aug. 2003)

Gardner, B. L. The economics of agricultural policies. New York: Macmillan Publishing Company, 1987. $387 \mathrm{p}$.

International Monetary Fund - IMF. International financial statistics (compact disc). Washington, Sep. 2000.

Marques, M. A política de sustentação de preços na comunidade econômica européia. Revista de Política Agrícola, v. 2, n. 3, p. 18-22, 1993.

Silveira, L. T; Burnquist, H. L. Uma análise da competitividade brasileira no mercado internacional de açúcar. (compact disc). In: Congresso Brasileiro de Economia e Sociologia Rural, 42. Cuiabá, 2003. Anais. Brasília: SOBER, 2004.

United Nations. Statistics division. Statistical databases. http://millenniumindicators.un.org/unsd/comtrade/dqBasicQuery.aspx (13 Sep. 2003). 